\title{
Review
}

\section{Indications for and Risks of Noninvasive Respiratory Support}

\author{
Kirsten Glaser ${ }^{\mathrm{a}} \quad$ Clyde J. Wright $^{\mathrm{b}}$ \\ aDivision of Neonatology, Department of Women's and Children's Health, University of Leipzig Medical Center,

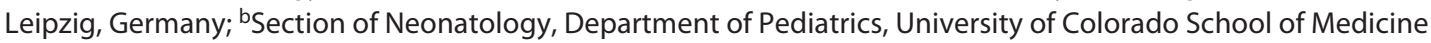 \\ and Children's Hospital Colorado, Aurora, CO, USA
}

\section{Keywords}

Noninvasive respiratory support - Preterm infant . Respiratory distress syndrome · Bronchopulmonary dysplasia - Continuous positive airway pressure

\begin{abstract}
Within the last decades, therapeutic advances have significantly improved the survival of extremely preterm infants. In contrast, the incidence of major neonatal morbidities, including bronchopulmonary dysplasia, has not declined. Given the well-established relationship between exposure to invasive mechanical ventilation and neonatal lung injury, neonatologists have sought for effective strategies of noninvasive respiratory support in high-risk infants. Continuous positive airway pressure has replaced invasive mechanical ventilation for the initial stabilization and the treatment of respiratory distress syndrome. Today, noninvasive respiratory support has been adopted even in the tiniest babies with the highest risk of lung injury. Moreover, different modes of noninvasive respiratory support supplemented by a number of adjunctive measures and rescue strategies have entered clinical practice with the goal of preventing intubation or reintubation. However, does this unquestionably important paradigm shift to strategies focused on noninvasive support lull us into a false sense of security? Can we do better in (i) identifying those very immature preterm infants best
\end{abstract}

equipped for noninvasive stabilization, can we improve (ii) determinants of failure of noninvasive respiratory support in the individual infant and underlying etiology, and can we enhance (iii) success of noninvasive respiratory support and (iv) better prevent ultimate harm to the developing lung? With increased survival of infants at the highest risk of developing lung injury and an unchanging burden of bronchopulmonary dysplasia, we should question indiscriminate use of noninvasive respiratory support and address the above issues.

(c) 2021 S. Karger AG, Basel

\section{Introduction}

Bronchopulmonary dysplasia (BPD) affects nearly half of all babies born with birth weight $<1,000$ grams [1] Both exposure to and the duration of invasive mechanical ventilation (IMV) increase the risk of developing BPD [2, 3]. To date, no optimal mode of mechanical ventilation has been identified that reliably minimizes lung injury and prevents BPD [4-6]. These realities have driven the interest in providing and optimizing noninvasive respiratory support for very immature preterm infants. Unfortunately, studies reveal high rates of failure $[7,8]$, with about $50 \%$ of infants initially managed on noninvasive respiratory support subsequently requiring IMV [9-11]. 
In light of these findings, this review addresses the question whether the main contributors to failure could be identified early and more precisely, leading to improved success. With rates of BPD remaining high in very immature infants and with growing evidence of persistent pulmonary morbidity in BPD survivors even in the postsurfactant era [12, 13], we further raise the question of longterm effects of noninvasive respiratory support in this cohort.

\section{What Is the Indication for Noninvasive Respiratory Support in Preterm Infants?}

Physiologic and anatomic features unique to the preterm neonate result in a near universal requirement for respiratory support. Structural immaturity of conducting airways, combined with increased compliance of the chest wall, accounts for an inability to maintain functional residual capacity (FRC). Subsequent low lung volume, increased airway resistance, and decreased pulmonary compliance lead to increased work of breathing and contribute to respiratory failure. Over the past 50 years, multiple solutions have been proposed to address this physiology unique to the preterm lung, culminating in the introduction of continuous positive airway pressure (CPAP) by Gregory et al. [14] in 1971. By the late 1980s, the early and aggressive use of CPAP in very low birth weight infants was associated with significantly lower rates of $\mathrm{BPD}$ $[2,15,16]$.

While these early reports were encouraging, it was unknown whether noninvasive support would prevent lung injury in the growing numbers of surviving neonates born less mature and largely antenatal corticosteroid (ACS) exposed in the late 1990s and early 2000s [17]. In light of this, 3 RCTs were performed comparing early nasal CPAP with routine intubation and surfactant: COIN [9], SUPPORT [10], and the Vermont Oxford Network Delivery Room Management Trial (VON-DRM) [11]. These studies demonstrated that routine use of early CPAP prevents lung injury in high-risk infants, with a number needed to treat of 17.7 [7], 25 [18], and 35 [19]. All studies enrolled extremely low gestational age neonates (ELGAN), and rates of ACS were high (>90\%). Based on these results, the American Academy of Pediatrics and the European Consensus Guidelines recommend routine CPAP and early selective surfactant over primary intubation with prophylactic surfactant for extremely preterm infants at risk for respiratory distress syndrome (RDS) $[20,21]$.

\section{CPAP Failure in the Tiny Baby - Common and Preventable?}

Most published data demonstrate that routine and indiscriminate use of CPAP, based on gestational age or birth weight, results in a relatively consistent and high rate of failure, with the most immature neonates failing at the highest rates $[9,22,23]$. Data from RCTs report nearly $50 \%$ failure in the first week of life [9-11], a rate similar to published observational study numbers [22, 24-27]. Furthermore, $40-70 \%$ of infants randomized to early CPAP ultimately received surfactant [9-11]. In summary, neonatologists caring for ELGANs are facing 2 realities: (1) routine and even indiscriminate use of CPAP in high-risk neonates may decrease the burden of BPD and (2) the same routine and indiscriminate use is associated with high rates of failure, potentially exposing a subset of high-risk neonates to unintended harm in various respects.

Chest wall instability and subsequent inability to recruit and maintain FRC constitute a major cause of noninvasive ventilation (NIV) failure in the very tiny baby [28]. Therefore, prevention efforts have focused on effective recruitment of FRC, administration of noninvasive positive pressure, and prevention of apnea. Augmenting CPAP, different modes of NIV have been introduced, with nasal intermittent positive-pressure ventilation (NIPPV) being the alternative most frequently used to mitigate failure, in particular, in infants with poor respiratory drive (Table 1) [29-31]. Moreover, the use of sustained lung inflation, T-piece in the delivery room, optimized infant positioning, application of various interfaces and delivery devices, and early administration of caffeine have been studied. These interventions seem to be effective to variable degrees and have been reviewed elsewhere $[8,32,33]$.

\section{What Happens When Surfactant Deficiency Complicates Preterm Lung Physiology?}

The results of the first RCT using a natural porcine surfactant to treat severe RDS were published in 1988, convincingly demonstrating a reduction in air leak, death, and the combined outcome of death or BPD [34]. Additional trials helped to fine-tune surfactant therapy in the management of RDS and revealed a key thematic link between treatment and outcome: the earlier RDS was accurately diagnosed and appropriately treated with surfactant, the better the outcome. "Early" compared to "de- 


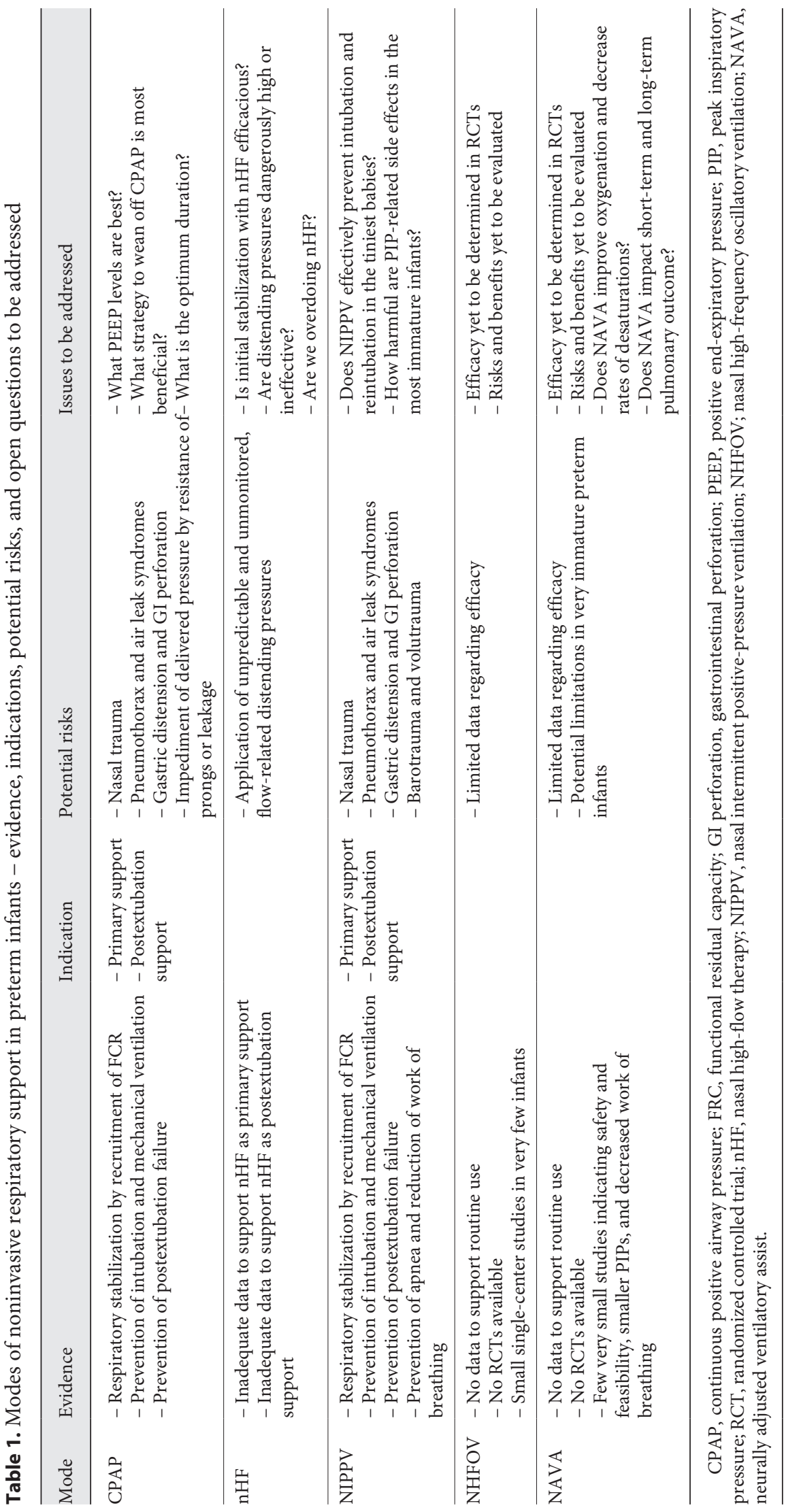


layed surfactant" improved survival and decreased air leak in preterm infants with RDS [35]. Guiding further studies, "prophylactic surfactant use" was proved to reduce air leak and mortality in infants at the highest risk of developing RDS [36-38], leading to the adoption of this approach in the USA and Europe [39].

In 2021, preterm infants at highest risk of RDS and later BPD differ significantly from subjects enrolled in the surfactant trials in the 1980s and early 1990s. While the Collaborative European Multicenter Study Group had enrolled subjects averaging 28.5 weeks of gestation [34], data from the NICHD Neonatal Research Network centers revealed increased survival from 1993 to 2012 in those born at 23,24, 25, and 27 weeks of gestation [17]. In this same population, rates of BPD were about $40-90 \%$ [17], indicating that the most vulnerable babies are surviving at rates higher than ever before, but with significant morbidities. The increase in ACS exposure from $24 \%$ in 1993 to $87 \%$ in 2010 [17] may have significantly contributed to this improved survival, contrasting with even lower rates of ACS exposure (about 30-40\%) in the early RCTs evaluating prophylactic surfactant [37].

In light of these fundamental changes in the NICU population, the results of the early surfactant trials might not be directly applicable to today's ACS exposed, ever increasingly less mature babies. In the 9 trials included in the Cochrane review published before 1999, prophylactic surfactant was superior to selective surfactant in terms of air leak and mortality [38]. In contrast, prophylactic surfactant provided no benefit and perhaps increased risk of harm, when compared to routine use of CPAP in a less mature population with near universal ACS exposure [38]. However, there may be logical and biologically plausible conclusions that still apply. It is likely to be true that if an extremely preterm baby has surfactant deficiency, the earlier the diagnosis is made and appropriately treated, the better the outcome will be. Neonatologists have to balance this reality with risks associated with intubation and IMV frequently accompanying surfactant administration. In fact, the use of imprecise measures to diagnose surfactant deficiency may lead to unnecessary harm. On the other hand, indiscriminate use of CPAP in high-risk neonates may potentially delay surfactant administration in a significant proportion of infants. Less-invasive surfactant administration represents a promising strategy to overcome this dilemma [40]. Alternatively, or additively, neonatologists need to better and earlier diagnose surfactant deficiency.

\section{Can We Discriminate Surfactant Deficiency from Other Causes of CPAP Failure?}

Any degree of surfactant deficiency will immediately compound the problems caused by the structural immaturity of conducting airways and the increased compliance of the chest wall. It is reasonable to hypothesize that NIV would be most successful and appropriately indicated for a patient population where chest wall instability and both recruitment and maintenance of FRC are not complicated by this condition [28]. The ability to make this diagnosis would not only allow identification of candidates with highest likelihood of being successfully managed on noninvasive support but would also allow for early and targeted diagnosis-based surfactant therapy.

Interestingly, observational data demonstrate that CPAP failure occurs early (about $8 \mathrm{~h}$ ), with incidences highly depending on the failure criteria used $[22,25,41-$ 43]. These data are remarkably consistent with those reported in the CURPAP and COIN trials where most babies failing CPAP (about 50\%) were intubated for increasing oxygen need within the first $8 \mathrm{~h}$ of life $[9,44]$. The early timing of failure would be consistent with the hypothesis that surfactant deficiency is a significant contributor to the inability to stabilize these babies with noninvasive support.

If surfactant deficiency is a primary cause of CPAP failure in ELGANs, it would be reasonable to expect currently available diagnostic tests to support this diagnosis. However, published data regarding the relationship between RDS determined by chest radiograph and CPAP failure are less compelling. The presence of severe RDS on chest X-ray was associated with an increased odds of CPAP failure [24, 43, 45]. However, failure is not uniform among those infants with severe RDS, occurring in 50-80\% [24, 45]. Furthermore, among those failing CPAP, less than a third have radiologic evidence of severe RDS [22, 43, 45]. These data, demonstrating that not every baby with severe RDS fails CPAP and that a minority of babies failing has severe RDS on X-ray, might indicate that the contribution of surfactant deficiency to CPAP failure in this population is overestimated. If this assumption is wrong, on the contrary, and if surfactant deficiency is a major cause of early CPAP failure, these data demonstrate the limited accuracy and value of chest radiographs in the diagnosis of this condition. 
Table 2. Criteria defining CPAP failure used in RCT comparing CPAP versus prophylactic surfactant

\begin{tabular}{llll}
\hline \multirow{2}{*}{$\begin{array}{l}\text { Trial } \\
\text { year }\end{array}$} & $\mathrm{FiO}_{2}$ & \\
\hline COIN [9] & 2008 & $>60 \%$ & oxygen saturation targets \\
\hline SUPPORT [10] & 2010 & $>50 \%$ & Not stated \\
\hline VON (Dunn) [11] & 2011 & $\begin{array}{l}\text { Mandatory: }>60 \% \\
\text { Discretionary: } 40-60 \%\end{array}$ & Maintain $\geq 88 \%$ \\
\hline
\end{tabular}

CPAP, continuous positive airway pressure.

\section{Does Increasing Oxygen Need Indicate that the Baby Is Not a Candidate for Noninvasive Support?}

In the absence of diagnostic testing, clinical criteria, such as oxygen requirement, are used to support the diagnosis of RDS. Both in the RCTs of surfactant performed in the 1980s and 1990s and the RCTs of CPAP in the 2000s, oxygen need $\left(\mathrm{FiO}_{2}\right)$ was incorporated into the definition of "treatment failure." In general, the early trials incorporated $\mathrm{FiO}_{2}$ requirement of about $40 \%$ to demonstrate presence of RDS prior to randomization [46]. In contrast, the later trials of CPAP incorporated higher $\mathrm{FiO}_{2}$ requirement (range 40-60\%, Table 2). While the finding of increasing $\mathrm{FiO}_{2}$ requirement is consistent with the diagnosis of surfactant deficiency, clarification is needed to what extent $\mathrm{FiO}_{2}$ provides adequate sensitivity and specificity to distinguish those babies on noninvasive support that would benefit from surfactant replacement therapy. Lacking clear data, there is no consensus on what $\mathrm{FiO}_{2}$ requirement defines threshold for intubation and subsequent surfactant administration in extremely preterm infants on CPAP. The European Guidelines recommend surfactant treatment at an $\mathrm{FiO}_{2}$ of 0.30 , Canadian Guidelines recommend 0.50, while the Committee on Fetus and Newborn of the American Academy of Pediatrics do not identify a specific level $[20,21,47]$.

Fuchs et al. [25] demonstrated how changing the $\mathrm{FiO}_{2}$ criteria affected intubation rates of extremely preterm infants on CPAP. In this study, intubation occurred when the $\mathrm{FiO}_{2}$ reached 0.60. By dropping the $\mathrm{FiO}_{2}$ criteria to $0.35,16 \%$ more infants required intubation and received surfactant and were treated about $2.5 \mathrm{~h}$ earlier. Additionally, an $\mathrm{FiO}_{2}$ of 0.30 at NICU admission had a sensitivity of $60 \%$ in predicting CPAP failure. These data reveal the fundamental limitations of oxygen requirement to guide surfactant therapy. Choosing a lower threshold allows a more inclusive approach and achieves earlier treatment. Alternatively, while a higher threshold maximizes the number of babies that will ultimately be successfully managed with CPAP, this selective approach will delay surfactant administration in some babies. Complicating this issue further, there may be some babies that never reach the set threshold for surfactant therapy although they are truly surfactant deficient and would benefit from treatment. Finally, there may be some extremely preterm babies that require supplemental oxygen for reasons not related to surfactant deficiency who reach the set threshold and do not benefit from this intervention. Given the therapeutic inaccuracies dictated by the loose association between $\mathrm{FiO}_{2}$ and surfactant deficiency, advanced diagnostic approaches are needed.

\section{Can We Identify Those That Will Succeed on Noninvasive Support by Accurately Diagnosing Surfactant Deficiency?}

In order to identify infants with the highest likelihood of being successfully managed on noninvasive support, accurate tests to diagnose surfactant deficiency are needed. Given what is known about the benefit of early surfactant administration, it is essential that a diagnostic test can be done early, quickly, and in extremely preterm infants. Ideally, the test would be easy to perform and noninvasive. Lung ultrasound (LUS) has been shown useful in diagnosing various conditions in pediatric patients [48, 49] and has been used to diagnose RDS in extremely preterm infants. This test can be done quickly and early, with reliable data being obtained as early as 5-10 min after birth [50-55]. Importantly, findings on early LUS consistent with the diagnosis of surfactant deficiency correlate well with alveolar-arterial gradient, oxygenation index, and arterial-to-alveolar ratio. These relationships are more reliable in very immature infants [51]. The presence of these findings is superior to chest radiograph and can aid in predicting CPAP failure [50-52, 54-56]. Perhaps 
even more importantly, published observational, quality improvement, and RCT data demonstrate that use of LUS may result in earlier administration of surfactant and decreased oxygen exposure [53, 54,57].

While these results are promising, there is one significant limitation. In these trials, the threshold for CPAP failure in extremely preterm infants was defined as requiring $\mathrm{FiO}_{2}>0.30[52-54,56]$. By using this $\mathrm{FiO}_{2}$ level and creating a more inclusive definition of CPAP failure, whether routine use of LUS improves the ability of the clinician to identify extremely preterm infants with the highest likelihood of succeeding on noninvasive support is left unanswered. Ideally, LUS could be used to further refine and target surfactant therapy. This nuanced perspective is conceptualized by considering the "false positive" (reported at 12-50\%) and "false negative" (reported at 5-23\%) LUS findings [51, 52, 54-56]. Whether the "false positives" - infants that demonstrate LUS findings consistent with RDS but never reach $\mathrm{FiO}_{2}$ of 0.30 - would benefit from surfactant therapy resulting in less oxygen exposure and lower positive pressure requirement is unknown. Alternatively, whether the "false negatives" meaning those without LUS findings of RDS but reaching a threshold of 0.30 - could or should be managed with noninvasive support without surfactant is unanswered. Hopefully, with increased use of LUS in this population, these answers will become clear.

\section{Why We Need to Fine-Tune the Indication for Noninvasive Respiratory Support}

Indiscriminate use of noninvasive respiratory support may cause potential harm including nasal trauma, pneumothorax and air leak syndromes, gastrointestinal distension and perforation, and barotrauma and volutrauma (Table 1). Infants randomized to CPAP showed higher rates of pneumothorax in the COIN trial ( 9 vs. $3 \%$ in ventilated infants) [9] and in the Colombian Neonatal Network Study (9 vs. 2\% in early surfactant therapy) [58], while rates did not differ between early CPAP and mechanical ventilation in the SUPPORT trial [10]. Also, a meta-analysis covering COIN, SUPPORT, CURPAP, and VON-DRM trials did not confirm this association [18]. A recent Cochrane review comparing CPAP with oxygen treatment alone described an increased risk of pneumothorax associated with CPAP, with a number needed to treat for an additional harmful outcome of 11 [59].

Gastric distension is observed with CPAP and NIPPV, and trials have reported cases of gastrointestinal perfora- tion and necrotizing enterocolitis [9-11]. Moreover, concerns about increased risk of intracerebral hemorrhage were raised in early studies of CPAP in preterm infants [60]. COIN, SUPPORT, and VON-DRM trials did not find significant differences in high-grade intraventricular hemorrhage, necrotizing enterocolitis, patent ductus arteriosus, and severe retinopathy of prematurity, with early CPAP versus elective intubation and IMV [9-11]. Moreover, the existing meta-analysis covering these trials did not confirm any association [18]. Cochrane reviews comparing CPAP and NIPPV did not find increased risk ratio for one modality [29-31]. Nevertheless, NIV can cause all adverse effects associated with IMV apart from intubation-related risks [29-31]. Therefore, routine use of NIPPV in nonapneic infants constitutes an unjustified escalation of noninvasive support. Depending on the leakage of prongs or mask and the intrinsic resistance, on the contrary, there is the additional risk of decreased transmission of the desired distending pressure.

In nasal high-flow therapy (nHF), distending pressures are unpredictable and unmonitored [61]. Preclinical models show that high pressures can be transmitted to infants if adequate leakage or pressure-relief valves are not present $[62,63]$. Vice versa, set flow, resistance, and leak through nares and mouth account for little to no delivery of distending pressures in many other babies. Although increased comfort and reduced nasal trauma [61] tempt practitioners to continuously expand nHF use, potential risks need to be critically reviewed. A Cochrane review concluded that there are inadequate data on $\mathrm{nHF}$ use in extremely preterm infants [61].

Data on the effect of NIV on long-term outcome in preterm infants are scarce. A longitudinal follow-up of infants $\leq 28$ weeks of gestation comparing 3 periods of respiratory management (1991-1992 vs. 1997 vs. 2005) found increased rates of BPD and worsened lung function at 8 years of age in the 2005 cohort versus earlier periods, despite an increased use of NIV over time [13]. The use of postnatal steroids decreased significantly from $40 \%$ in $1991-1992$ to $23 \%$ in 2005 , while survival rates increased (53 vs. $65 \%$ ) [13], suggesting that highest-risk infants did not survive long enough to develop BPD in the early cohort. Given the more frequent use of NIV, however, these findings raise the question of long-term effects of NIV. Respiratory follow-up of the SUPPORT study population documented fewer episodes of wheezing ( 28.9 vs. $36.5 \%$, $p<0.05)$, respiratory illnesses ( 47.7 vs. $55.2 \%, p<0.05$ ), and physician visits for breathing problems (68.0 vs. $72.9 \%, p<0.05)$ in the CPAP group compared to infants randomized to intubation/surfactant at 18-22 months 
corrected age [64]. Moreover, the 2 SUPPORT study groups did not differ in the composite outcome of death/ neurodevelopmental impairment (10.9 vs. 9.1\%, CPAP vs. intubation/surfactant) at 18-22 months corrected age [64].

By trying to avoid IMV, neonatologists might run the risk of overdoing noninvasive support. Using higher thresholds for intubation and reintubation will increase the number of babies managed on noninvasive support. It is critical to weigh risks of intubation against prolonged exposure to episodes of apnea or worsening RDS. Contrariwise, care must be taken to avoid adverse hyperinflation of the airways and gastrointestinal tract.

\section{Conclusions}

The widespread use of noninvasive respiratory support in very immature infants unquestionably constitutes an important paradigm shift in neonatal care. Though the physiologic basis and the noninvasive character of NIV are convincing, it is somewhat disappointing that current approaches do not result in larger short-term and longterm treatment effects. Early identification of infants that benefit most from noninvasive support versus those who need intubation and targeted surfactant therapy seems key to maximize benefit and limit harm. A "one strategy fits all" approach does not meet individual needs affected by gestational age and other determinants, and indications for noninvasive support in the absence of surfactant treatment will fail to capture the patient population that benefit most and exclude those who do not. In this context, less-invasive surfactant administration constitutes a promising approach allowing surfactant administration without intubation. Of note, the potential benefit of this approach might be higher than assessed so far. With cri- teria often relying on very inclusive $\mathrm{FiO}_{2}$ requirement, the observed effect may have been biased by including those who do not benefit from surfactant treatment and potentially by excluding some that do. LUS constitutes a promising tool in diagnosing RDS. Whether a combination of clinical findings, LUS, and biochemical assessment of maturation of surfactant production could further refine a more discriminate use of noninvasive support is unknown. Ultimately, strategies like these could usher in a new era of personalized neonatal medicine. Although risk of complications appears small, one cannot conclusively determine the long-term effects of noninvasive support. Proper selection of patients, modes, and instrument settings and constant re-evaluation is critical. The paucity of data on long-term outcome of high-risk infants managed with noninvasive support highlights the need for appropriate follow-up studies that take into account the shortcomings of BPD as a surrogate for pulmonary dysfunction and morbidity later in life.

\section{Conflict of Interest Statement}

K.G. or C.J.W. declare no potential conflicts of interest, real or perceived.

\section{Funding Sources} C.J.W.

This work was supported by NIH grant R01HL132941 to

\section{Author Contributions}

K.G. and C.J.W. equally contributed to this manuscript, being responsible for conception, design, and drafting of this work.

\section{References}

1 Stoll BJ, Hansen NI, Bell EF, Walsh MC, Carlo WA, Shankaran S, et al. Trends in care practices, morbidity, and mortality of extremely preterm neonates. JAMA. 2015;314:1039-51.

2 Van Marter LJ, Allred EN, Pagano M, Sanocka U, Parad R, Moore M, et al. Do clinical markers of barotrauma and oxygen toxicity explain interhospital variation in rates of chronic lung disease? The Neonatology Committee for the Developmental Network. Pediatrics. 2000;105(6):1194-201.

3 Laughon M, Bose C, Allred EN, O'Shea TM, Ehrenkranz RA, Van Marter LJ, et al. Antecedents of chronic lung disease following three patterns of early respiratory disease in preterm infants. Arch Dis Child Fetal Neonatal Ed. 2011;96(2):F114-20.

4 Courtney SE, Durand DJ, Asselin JM, Hudak ML, Aschner JL, Shoemaker CT, et al. Highfrequency oscillatory ventilation versus conventional mechanical ventilation for verylow-birth-weight infants. N Engl J Med. 2002; 347(9):643-52.

5 Ramanathan R. Optimal ventilatory strategies and surfactant to protect the preterm lungs. Neonatology. 2008;93(4):302-8.

6 Wheeler K, Klingenberg C, McCallion N, Morley CJ, Davis PG. Volume-targeted versus pressure-limited ventilation in the neonate. Cochrane Database Syst Rev. 2010;10(11): CD003666.

7 Wright CJ, Polin RA, Kirpalani H. Continuous positive airway pressure to prevent neonatal lung injury: how did we get here, and how do we improve? J Pediatr. 2016;173:17e2.

8 Wright CJ, Sherlock LG, Sahni R, Polin RA. Preventing continuous positive airway pressure failure: evidence-based and physiologically sound practices from delivery room to the neonatal intensive care unit. Clin Perinatol. 2018;45(2):257-71. 
9 Morley CJ, Davis PG, Doyle LW, Brion LP, Hascoet JM, Carlin JB, et al. Nasal CPAP or intubation at birth for very preterm infants. $\mathrm{N}$ Engl J Med. 2008;358(7):700-8.

10 Finer NN, Finer NN, Carlo WA, Walsh MC, Rich W, Gantz MG, et al. Early CPAP versus surfactant in extremely preterm infants. N Engl J Med. 2010;362(21):1970-9.

11 Dunn MS, Kaempf J, de Klerk A, de Klerk R, Reilly M, Howard D, et al. Randomized trial comparing 3 approaches to the initial respiratory management of preterm neonates. Pediatrics. 2011;128(5):e1069-76.

12 Davidson LM, Berkelhamer SK. Bronchopulmonary dysplasia: chronic lung disease of infancy and long-term pulmonary o.utcomes. J Clin Med. 2017;6(1):4.

13 Doyle LW, Carse E, Adams AM, Ranganathan S, Opie G, Cheong JLY, et al. Ventilation in extremely preterm infants and respiratory function at 8 years. N Engl J Med. 2017; 377(4):329-37.

14 Gregory GA, Kitterman JA, Phibbs RH, Tooley WH, Hamilton WK. Treatment of the idiopathic respiratory-distress syndrome with continuous positive airway pressure. $\mathrm{N}$ Engl J Med. 1971;284(24):1333-40.

15 Avery ME, Tooley WH, Keller JB, Hurd SS, Bryan $\mathrm{MH}$, Cotton $\mathrm{RB}$, et al. Is chronic lung disease in low birth weight infants preventable? A survey of eight centers. Pediatrics. 1987;79(1):26-30.

16 Gittermann MK, Fusch C, Gittermann AR, Regazzoni BM, Moessinger AC. Early nasal continuous positive airway pressure treatment reduces the need for intubation in very low birth weight infants. Eur J Pediatr. 1997; 156(5):384-8.

17 Stoll BJ, Hansen NI, Bell EF, Walsh MC, Carlo WA, Shankaran S, et al. Trends in care practices, morbidity, and mortality of extremely preterm neonates, 1993-2012. JAMA. 2015;314(10):1039-51.

18 Schmolzer GM, Kumar M, Pichler G, Aziz K, O'Reilly M, Cheung PY. Non-invasive versus invasive respiratory support in preterm infants at birth: systematic review and metaanalysis. BMJ. 2013;347:f5980.

19 Fischer HS, Bührer C. Avoiding endotracheal ventilation to prevent bronchopulmonary dysplasia: a meta-analysis. Pediatrics. 2013 132(5):e1351-60.

20 Committee on Fetus and Newborn, American Academy of Pediatrics. Respiratory support in preterm infants at birth. Pediatrics. 2014; 133(1):171-4.

21 Sweet DG, Carnielli V, Greisen G, Hallman M, Ozek E, Te Pas A, et al. European consensus guidelines on the management of respiratory distress syndrome: 2019 update. Neonatology. 2019;115(4):432-50.

22 Dargaville PA, Aiyappan A, De Paoli AG, Dalton RG, Kuschel CA, Kamlin CO, et al. Continuous positive airway pressure failure in preterm infants: incidence, predictors and consequences. Neonatology. 2013;104(1):814.
23 Roberts CT, Owen LS, Frøisland DH, Doyle LW, Davis PG, Manley BJ. Predictors and outcomes of early intubation in infants born at 28-36 weeks of gestation receiving noninvasive respiratory support. J Pediatr. 2020; 216:109-e1.

24 Ammari A, Suri M, Milisavljevic V, Sahni R, Bateman D, Sanocka U, et al. Variables associated with the early failure of nasal CPAP in very low birth weight infants. J Pediatr. 2005; 147(3):341-7.

25 Fuchs H, Lindner W, Leiprecht A, Mendler MR, Hummler HD. Predictors of early nasal CPAP failure and effects of various intubation criteria on the rate of mechanical ventilation in preterm infants of mechanical ventilation in preterm infants of $<29$ weeks. Arch Dis Child Fetal Neonatal Ed. 2011;96(5):F343-7.

26 Dargaville PA, Gerber A, Johansson S, De Paoli AG, Kamlin CO, Orsini F, et al. Australian, New Zealand Neonatal Network. Incidence and outcome of CPAP failure in preterm infants. Pediatrics. 2016; 138(1): e20153985.

27 Gulczynska E, Szczapa T, Hozejowski R, Borszewska-Kornacka MK, Rutkowska M. Fraction of inspired oxygen as a predictor of CPAP failure in preterm infants with respiratory distress syndrome: a prospective multicenter study. Neonatology. 2019;116:171-8.

28 Bancalari $\mathrm{EH}$, Jobe $\mathrm{AH}$. The respiratory course of extremely preterm infants: a dilemma for diagnosis and terminology. J Pediatr. 2012;161(4):585-8.

29 Lemyre B, Davis PG, de Paoli AG. Nasal intermittent positive pressure ventilation (NIPPV) versus nasal continuous positive airway pressure (NCPAP) for apnea of prematurity. Cochrane Database Syst Rev. 2002(1):CD002272.

30 Lemyre B, Laughon M, Bose C, Davis PG. Early nasal intermittent positive pressure ventilation (NIPPV) versus early nasal continuous positive airway pressure (NCPAP) for preterm infants. Cochrane Database Syst Rev. 2016;12:CD005384.

31 Lemyre B, Davis PG, De Paoli AG, Kirpalani $H$. Nasal intermittent positive pressure ventilation (NIPPV) versus nasal continuous positive airway pressure (NCPAP) for preterm neonates after extubation. Cochrane Database Syst Rev. 2017;2(9):CD003212.

32 Sahni R, Schiaratura M, Polin RA. Strategies for the prevention of continuous positive airway pressure failure. Semin Fetal Neonatal Med. 2016;21(3):196-203.

33 Patel RM, Zimmerman K, Carlton DP, Clark R, Benjamin DK, Smith PB. Early caffeine prophylaxis and risk of failure of initial continuous positive airway pressure in very low birth weight infants. J Pediatr. 2017;190:108e1.

34 Collaborative European Multicenter Study Group. Surfactant replacement therapy for severe neonatal respiratory distress syndrome: an international randomized clinical trial. Pediatrics. 1988;82:683-91.
35 Yost CC, Soll RF. Early versus delayed selective surfactant treatment for neonatal respiratory distress syndrome. Cochrane Database Syst Rev. 2000;11(2):CD001456.

36 Morley CJ. Systematic review of prophylactic vs rescue surfactant. Arch Dis Child Fetal Neonatal Ed. 1997;77(1):F70-4.

37 Soll RF, Morley CJ. Prophylactic versus selective use of surfactant in preventing morbidity and mortality in preterm infants. Cochrane Database Syst Rev. 2001(2):CD000510.

38 Rojas-Reyes MX, Morley CJ, Soll R. Prophylactic versus selective use of surfactant in preventing morbidity and mortality in preterm infants. Cochrane Database Syst Rev. 2012; 3(3):CD000510.

39 Horbar JD, Carpenter JH, Buzas J, Soll RF, Suresh G, Bracken MB, et al. Timing of initial surfactant treatment for infants 23 to 29 weeks' gestation: is routine practice evidence based? Pediatrics. 2004;113(6):1593-602.

40 Herting E, Härtel C, Göpel W. Less invasive surfactant administration (LISA): chances and limitations. Arch Dis Child Fetal Neonatal Ed. 2019;104(6):F655-9.

41 De Jaegere AP, van der Lee JH, Canté C, van Kaam AH. Early prediction of nasal continuous positive airway pressure failure in preterm infants less than 30 weeks gestation. Acta Paediatr. 2012;101(4):374-9.

42 Rocha G, Flôr-de-Lima F, Proença E, Carvalho C, Quintas C, Martins T, et al. Failure of early nasal continuous positive airway pressure in preterm infants of 26 to 30 weeks gestation. J Perinatol. 2013;33(4):297-301.

43 Kakkilaya V, Wagner S, Mangona KLM, Steven Brown L, Jubran I, He H, et al. Early predictors of continuous positive airway pressure failure in preterm neonates. J Perinatol. 2019; 39(8):1081-8.

44 Sandri F, Plavka R, Ancora G, Simeoni U, Stranak Z, Martinelli S, et al. Prophylactic or early selective surfactant combined with nCPAP in very preterm infants. Pediatrics. 2010; 125(6):e1402-9.

45 Tagliaferro T, Bateman D, Ruzal-Shapiro C, Polin RA. Early radiologic evidence of severe respiratory distress syndrome as a predictor of nasal continuous positive airway pressure failure in extremely low birth weight newborns. J Perinatol. 2015;35(2):99-103.

46 Seger N, Soll R. Animal derived surfactant extract for treatment of respiratory distress syndrome. Cochrane Database Syst Rev. 2009(2): CD007836.

$47 \mathrm{Ng} \mathrm{EH}$, Shah V. Guidelines for surfactant replacement therapy in neonates. Paediatr Child Health. 2021;26(1):35-49.

48 Dietrich CF, Buda N, Ciuca IM, Dong Y, Fang C, Feldkamp A, et al. Lung ultrasound in children, WFUMB review paper (part 2). Med Ultrason. 2021 Mar 3 [Online ahead of print].

49 Jaworska J, Buda N, Ciuca IM, Dong Y, Fang C, Feldkamp A, et al. Ultrasound of the pleura in children, WFUMB review paper. Med Ultrason. 2021 Feb 1 [Online ahead of print]. 
50 Raimondi F, Migliaro F, Sodano A, Ferrara T, Lama S, Vallone G, et al. Use of neonatal chest ultrasound to predict noninvasive ventilation failure. Pediatrics. 2014;134(4):e1089-94.

51 Brat R, Yousef N, Klifa R, Reynaud S, Shankar Aguilera S, De Luca D. Lung ultrasonography score to evaluate oxygenation and surfactant need in neonates treated with continuous positive airway pressure. JAMA Pediatr. 2015; 169(8):e151797.

52 Perri A, Riccardi R, Iannotta R, Di Molfetta DV, Arena R, Vento G, et al. Lung ultrasonography score versus chest $\mathrm{x}$-ray score to predict surfactant administration in newborns with respiratory distress syndrome. Pediatr Pulmonol. 2018;53(9):1231-6.

53 Rodriguez-Fanjul J, Jordan I, Balaguer M, Batista-Muñoz A, Ramon M, Bobillo-Perez S. Early surfactant replacement guided by lung ultrasound in preterm newborns with RDS: the ULTRASURF randomised controlled trial. Eur J Pediatr. 2020;179(12):1913-20.

54 Aldecoa-Bilbao V, Balcells-Esponera C, Herranz Barbero A, Borràs-Novell C, Izquierdo Renau M, Iriondo Sanz M, et al. Lung ultrasound for early surfactant treatment: development and validation of a predictive model. Pediatr Pulmonol. 2021;56(2):433-41.
55 Badurdeen S, Kamlin COF, Rogerson SR, Kane SC, Polglase GR, Hooper SB, et al. Lung ultrasound during newborn resuscitation predicts the need for surfactant therapy in very- and extremely preterm infants. Resuscitation. 2021 Feb 3 [Online ahead of print].

56 De Martino L, Yousef N, Ben-Ammar R, Raimondi F, Shankar-Aguilera S, De Luca D. Lung ultrasound score predicts surfactant need in extremely preterm neonates. Pediatrics. 2018;142(3):e20180463.

57 Raschetti R, Yousef N, Vigo G, Marseglia G, Centorrino R, Ben-Ammar R, et al. Echography-guided surfactant therapy to improve timeliness of surfactant replacement: a quality improvement project. J Pediatr. 2019;212: 137-e1.

58 Rojas MA, Lozano JM, Rojas MX, Laughon $\mathrm{M}$, Bose CL, Rondon MA, et al. Very early surfactant without mandatory ventilation in premature infants treated with early continuous positive airway pressure: a randomized, controlled trial. Pediatrics. 2009;123(1):137-42.

59 Ho JJ, Subramaniam P, Davis PG. Continuous positive airway pressure (CPAP) for respiratory distress in preterm infants. Cochrane Database Syst Rev. 2020;10:CD002271.
60 Pape KE, Armstrong DL, Fitzhardinge PM. Central nervous system patholgoy associated with mask ventilation in the very low birthweight infant: a new etiology for intracerebellar hemorrhages. Pediatrics. 1976;58(4):47383.

61 Wilkinson D, Andersen C, O’Donnell CP, De Paoli AG, Manley BJ. High flow nasal cannula for respiratory support in preterm infants. Cochrane Database Syst Rev. 2016;2: CD006405.

62 Nielsen KR, Ellington LE, Gray AJ, Stanberry LI, Smith LS, DiBlasi RM. Effect of high-flow nasal cannula on expiratory pressure and ventilation in infant, pediatric, and adult models. Respir Care. 2018;63(2):147-57.

63 Ejiofor BD, Carroll RW, Bortcosh W, Kacmarek RM. PEEP generated by high-flow nasal cannula in a pediatric model. Respir Care. 2019;64(10):1240-9.

64 Stevens TP, Finer NN, Carlo WA, Szilagyi PG, Phelps DL, Walsh MC, et al. SUPPORT Study Group of the Eunice Kennedy Shriver National Institute of Child Health and Human Development Neonatal Research Network. Respiratory outcomes of the surfactant positive pressure and oximetry randomized trial (SUPPORT). J Pediatr. 2014;165:240-9.e4 